\title{
Shh/Boc Signaling Is Required for Sustained Generation of Ipsilateral Projecting Ganglion Cells in the Mouse Retina
}

\author{
Luisa Sánchez-Arrones, ${ }^{1,2,3 *}$ Francisco Nieto-Lopez, ${ }^{1,2,3 *}$ Cristina Sánchez-Camacho, ${ }^{2,3}$ M. Isabel Carreres, ${ }^{4}$ \\ Eloisa Herrera, ${ }^{4}$ Ami Okada, ${ }^{5}$ and Paola Bovolenta ${ }^{1,2,3}$ \\ ${ }^{1}$ Centro de Biología Molecular Severo Ochoa, Consejo Superior de Investigaciones Científicas-Universidad Autónoma de Madrid, Madrid 28049, Spain, \\ ${ }^{2}$ CIBER de Enfermedades Raras, Madrid 28049, Spain, ${ }^{3}$ Instituto Cajal, Consejo Superior de Investigaciones Científicas, Madrid 28002, Spain, ${ }^{4}$ Instituto de \\ Neurociencias, Consejo Superior de Investigaciones Científicas-Universidad Miguel Hernández de Elche, Alicante 03550, Spain, and ${ }^{5}$ Stanford University, \\ Department Neurology, Stanford, California 94305
}

Sonic Hedgehog (Shh) signaling is an important determinant of vertebrate retinal ganglion cell (RGC) development. In mice, there are two major RGC populations: (1) the Islet2-expressing contralateral projecting (c)RGCs, which both produce and respond to Shh; and (2) the Zic2-expressing ipsilateral projecting RGCs (iRGCs), which lack Shh expression. In contrast to cRGCs, iRGCs, which are generated in the ventrotemporal crescent (VTC) of the retina, specifically express Boc, a cell adhesion molecule that acts as a high-affinity receptor for Shh. In $\mathrm{Boc}^{-/-}$mutant mice, the ipsilateral projection is significantly decreased. Here, we demonstrate that this phenotype results, at least in part, from the misspecification of a proportion of iRGCs. In $B o c^{-/-}$VTC, the number of Zic2-positive RGCs is reduced, whereas more Islet2/Shh-positive RGCs are observed, a phenotype also detected in Zic2 and Foxd1 null embryos. Consistent with this observation, organization of retinal projections at the dorsal lateral geniculate nucleus is altered in $\mathrm{Boc}^{-/-}$mice. Analyses of the molecular and cellular consequences of introducing Shh into the developing VTC and Zic2 and Boc into the central retina indicate that Boc expression alone is insufficient to fully activate the ipsilateral program and that Zic2 regulates Shh expression. Taking these data together, we propose that expression of Boc in cells from the VTC is required to sustain Zic2 expression, likely by regulating the levels of Shh signaling from the nearby cRGCs. Zic2, in turn, directly or indirectly, counteracts Shh and Islet2 expression in the VTC and activates the ipsilateral program.

\section{Introduction}

Retinal ganglion cells (RGCs), the output neurons of the vertebrate retina, relay information to the brain regions that mediate image-forming vision. Binocular vision differs among vertebrates and is dictated by the proportion of crossing and noncrossing RGC axons at the chiasm. Although local guidance factors are critical to midline fiber segregation, axon competence to respond to these cues is imposed by cellautonomous programs that specify RGC identity (Erskine and Herrera, 2007).

Received April 30, 2012; revised March 20, 2013; accepted March 22, 2013.

Author contributions: E.H. and P.B. designed research; L.S.-A., F.N.-L., C.S.-C., M.I.C., and A.O. performed research; A.O. contributed unpublished reagents/analytic tools; L.S.-A., F.N.-L., C.S.-C., E.H., and P.B. analyzed data; L.S.-A. and P.B. wrote the paper.

This work was supported by Spanish Ministerio de Ciencia e Innovación (MICINN) Grant BFU2010-16031, Comunidad Autonoma de Madrid Grant S2010/BMD-2315, a CIBER de Enfermedades Raras grant to P.B.; and Spanish MICINN Grant BFU2011-16563 and CONSOLIDER-Ingenio Program Grant CDS2007-023 to E.H. We thank Elisa Marti for critical reading of the manuscript; Celia Vegar for mice genotyping; Dr. Corey Harwell for providing some of the $\mathrm{Boc}^{-1-}$ embryos used in the revision of this manuscript; and the RIKEN BioResource Center (Japan) for the Zic2 mutant mice.

*L.S.-A. and F.N.-L. contributed equally to this work.

The authors declare no competing financial interests.

Correspondence should be addressed to Dr. Paola Bovolenta, Centro de Biología Molecular Severo 0choa, Consejo Superior de Investigaciones Científicas-UAM, c/Nicolas Cabrera, 1, Cantoblanco, Madrid 28049, Spain; E-mail: pbovolenta@cbm.uam.es.

C. Sánchez-Camacho's present address: Universidad Europea de Madrid, c/ Tajo, s/n Villaviciosa de Odón, Madrid 28670, Spain.

DOI:10.1523/JNEUROSCI.2083-12.2013

Copyright $\odot 2013$ the authors $\quad 0270-6474 / 13 / 338596-12 \$ 15.00 / 0$
The vast majority of RGCs in mice, which have a relatively small binocular field, project to the contralateral side of the brain (cRGCs), whereas a small proportion projects to the ipsilateral side (iRGCs). iRGCs are generated during early embryonic development only in the ventrotemporal crescent (VTC), whereas cRGCs are specified throughout the retina, including in the VTC, where they intermingle with the iRGCs starting from E17 (Drager, 1985).

The transcriptional network that establishes cRGC identity involves the POU-domain Brn3b and the LIM-homeodomain Islet2 (Mu and Klein, 2004), both of which contribute to axoncrossing behavior (Erkman et al., 2000; Wang et al., 2002; Pak et al., 2004). Committed RGCs express the morphogen Shh under the control of Brn3b (Mu et al., 2004). Shh, in turn, signals to the nearby cells propagating the wave of RGC differentiation, their final number, maturation (Esteve and Bovolenta, 2006), and their axon extension along the proximal visual pathway (Sánchez-Camacho and Bovolenta, 2009). Shh, produced by midline cells at the chiasm borders, further help guide visual axons by constraining their growth along the anteroposterior axis (Trousse et al., 2001; Sánchez-Camacho and Bovolenta, 2008).

The genetic program involved in the generation of iRGC differs from that of cRGCs and requires Foxd1-mediated activation of Zic2 (Herrera et al., 2003; Herrera et al., 2004), a zinc-finger transcription factor. Zic2 activates the expression of ipsilaterality effectors, including the EphB1 receptor and the serotonin transporter (Sert) (Lee et al., 2008, Garcia-Frigola and Herrera, 2010). 
In contrast to cRGCs, iRGCs lack Shh expression but specifically express Boc (brother of Cdon) (Sánchez-Camacho and Bovolenta, 2008), a high-affinity Shh receptor (Tenzen et al., 2006) that mediates the Shh role in axon guidance (Okada et al., 2006). Indeed, it has been recently proposed that Boc expression by iRGCs is required to prevent ipsilateral axons from crossing the optic chiasm midline (Fabre et al., 2010). However, there is also evidence that $\mathrm{Shh} / \mathrm{Boc}$ signaling contributes to cell fate specification (Bergeron et al., 2011) and that Shh and Zic2 could influence each others' expression during forebrain patterning (Brown et al., 2003; Sanek et al., 2009). Here we have investigated whether Boc/ Shh signaling participates in iRGC generation, and we have further explored Boc implication in iRGC axonal growth by analyzing the development of the ipsilateral component in the visual system of $\mathrm{Boc}^{-/-}$mice and the effect that Zic2 loss-offunction and Shh gain-of-function has in VTC development. Our study demonstrates that a regulatory loop between Zic2 and Bocmediated Shh signaling is an important mechanism to maintain the appropriate number of iRGC in the retina. Disruption of this regulatory loop shifts RGC production in the VTC toward a cRGC fate, with consequent alterations in retinal fiber organization at one of their main targets, the dorsal lateral geniculate nucleus (dLGN).

\section{Materials and Methods}

Animals. Boc ${ }^{-/-}, Z i c 2^{k d / k d}$, and Foxd $1^{-/-}$mice were generated and bred as described (Hatini et al., 1996; Nagai et al., 2000; Okada et al., 2006). $\mathrm{Boc}^{-/-}$animals were maintained in both the CD1 and C57BL background. Analysis of the two strains led to comparable results; thus, the two lines were interchangeably used in this study. Of note, in the albino strain, the number of Zic2-positive cells in the VTC was slightly inferior to that observed in the C57BL background, possibly in line with recent observations on albino mice (Rebsam et al., 2012). These changes, however, were not significant. Embryos were obtained from homozygous or heterozygous timed mating. The phenotype of homozygous null embryos was always compared with littermates or age-matched wild-type (WT) derived from heterozygous mating. For electroporation experiments, C57BL embryos were used. The date of the vaginal plug was considered E0.5. Animals used in the study were of either sex. Animals were collected and handled following the Spanish (RD 223/88), European (86/609/ECC), and American (National Research Council, 1996) regulations.

DNA plasmids. The coding sequence of the mouse Boc gene was inserted in frame in the pEGFPN1 vector to generate a Boc::GFP fusion protein (Okada et al., 2006). The N-Shh::GFP construct was kindly provided by Prof. A.P. McMahon (Harvard University, Cambridge, MA). The coding sequences of the human ZIC2 and mouse Shh::GFP and $B o c:$ GFP were subcloned in the pCAG plasmid for electroporations (Garcia-Frigola et al., 2007).

In situ hybridization and immunohistochemistry. E13 to E15 embryos were fixed by immersion in 4\% PFA in phosphate buffer $0.1 \mathrm{M}, \mathrm{pH} 7.2$, for $3 \mathrm{~h}$. Embryos older than E15 and postnatal (P) animals were transcardially perfused with $4 \%$ PFA. Brains were dissected, postfixed for $2-12 \mathrm{~h}$ at $4^{\circ} \mathrm{C}$, washed in PBS, cryoprotected in $30 \%$ sucrose solution in phosphate buffer, and sectioned at $15 \mu \mathrm{m}$ thickness in the frontal plane. Sections were hybridized as described previously (Esteve et al., 2003), using the following digoxigenin-labeled specific probes: Shh, Zic2, Islet2, Sert, and Boc. Immunostaining was performed as described previously (Esteve et al., 2003) with the following antibodies: rabbit anti-Zic2 (1:5000; Millipore), goat antiCdon (1:100; R\&D Systems), rabbit anti-GFP (1:1000, Invitrogen), goat anti-Brn3b (1:500; Santa Cruz Biotechnology), guinea-pig anti-Islet2 (1: 8000 , a kind gift of Prof. T. Jessell), and rabbit anti-Phospho-Histone H3 (1:2000; Cell Signaling Technology). Secondary antibodies were conjugated to Alexa-594 and Alexa-488 (1:500; Invitrogen) or to biotin followed by streptavidin-POD (1:500; Jackson ImmunoResearch Laboratories) and revealed with DAB. Sections were counterstained with DAPI $(1 \mu \mathrm{g} / \mathrm{ml}$, Vector
Laboratories). Distribution of apoptotic cells was determined by TUNEL staining using the In Situ Cell Death Detection Kit, POD (Roche) following the manufacturer's directions.

Anterograde and retrograde labeling of retino-geniculate projections. WT and $\mathrm{Boc}^{-1-}$ animals (E16, E18, and P1-P4) were fixed in 4\% PFA from $1.5 \mathrm{~h}$ to overnight at $4^{\circ} \mathrm{C}$ and then washed in PBS. Small crystals of DiI (D282, Invitrogen) were implanted unilaterally into the exposed optic disc, as described (Godement et al., 1987). Heads were incubated at $37^{\circ} \mathrm{C}$ in PBS containing $0.4 \%$ PFA for 2-3 weeks. Brains were isolated, and the optic chiasm was viewed and photographed under fluorescent stereomicroscopy. Brains were then embedded in $4 \%$ agarose and sectioned with a vibratome (Leica) at $100 \mu \mathrm{m}$ thickness in the frontal or horizontal plane. Sections were analyzed with a Leica DM microscope equipped for epifluorescence. Alternatively, P12-P30 WT and $\mathrm{Boc}^{-1-}$ mice were anesthetized with isofluorane (Isova vet, reference 240055 Centauro), and eyes were filled with $0.5 \mu \mathrm{l}$ of cholera toxin subunit B (CTB) conjugated to Alexa-488 (green, right eye) or Alexa-594 (red, left eye; Invitrogen) as described previously (Rebsam et al., 2009). After 48 h, mice were anesthetized and perfused with $4 \%$ PFA. Brains were embedded in $4 \%$ agarose and sectioned in 50-60 $\mu \mathrm{m}$ frontal or horizontal sections. These were mounted and analyzed by confocal microscopy. For retrograde labeling, E17 embryos were traced using Dextran-Rhodamine (3000 MW; Invitrogen), as described previously (Herrera et al., 2003), but tissue was incubated at $37^{\circ} \mathrm{C}$ to allow complete backfilling.

In utero and ex utero electroporation. E13 pregnant mice were anesthetized with isofluorane as above and DNA introduced by electroporation in utero as described previously (Sánchez-Camacho and Bovolenta, 2008). Different DNA solutions $(2 \mu \mathrm{g} / \mu \mathrm{l}$; pCAG-GFP alone or combined with either pCAG-Boc, pCAG-Zic2, and pCAG-Foxd1 or pCAG-Shh::GFP and pCAG-Boc::GFP alone) were injected into one eye of each embryo through the uterine wall before electroporation. Mice were sutured and allowed to recover and develop for $5 \mathrm{~d}$, at which time E18.5 embryos were collected and fixed with 4\% PFA. Retinas were then removed, flat-mounted, and analyzed by fluorescent microscopy. Brains were isolated, and the trajectory of the electroporated RGC axons were viewed and photographed with a fluorescence stereomicroscope. Brains were then processed for cryotome or vibratome sectioning as described above. For ex utero electroporations, E13 WT embryos were collected, maintained in cold PBS, and different DNA solutions $(2 \mu \mathrm{g} / \mu \mathrm{l}$; pCAGGFP alone or combined with either pCAG-Boc, pCAG-Zic2) injected into one eye before electroporation. Afterward, the retinas were dissected and incubated in tissue culture dishes (Nunc) with DMEM/F12 (Invitrogen) and $\mathrm{N}-2$ supplement ( $1 \%$, Invitrogen) overnight at $37^{\circ} \mathrm{C}$.

$q R T-P C R$. E13 WT retinas were electroporated ex utero and maintained in culture as described above. After $24 \mathrm{~h}$, the GFP-positive regions from eight positive retinas were collected under fluorescence microscopy and processed for qRT-PCR as described previously (Beccari et al., 2012). Total RNA was extracted and purified following standard commercial protocols (RNeasy Mini Kit, QIAGEN). RNA was reverse-transcribed using the High-Capacity cDNA Reverse Transcription Kit (Applied Biosystems). The qPCR was performed using Power SYBR Green Master Mix following the manufacturer's protocol (Applied Biosystems) in a 25 $\mu \mathrm{l}$ reaction mixture containing $2 \mu \mathrm{l}$ of cDNA. Primers were designed using PrimerExpress (Applied Biosystems), and sequences are available upon request. In all cases, the length of the amplicons was between 100 and $150 \mathrm{bp}$. Transcript levels were normalized to $18 \mathrm{~S}$ rRNA levels and their level compared with that of GFP-electroporated controls. Data were analyzed with the Mann-Whitney test and considered significant with $p<0.05$.

Image and statistical analysis. Tissue was analyzed with an M205FA stereomicroscope or a DM CTR5000 microscope equipped for fluorescence microscopy and photographed with DFC350Fx and DFC500 cameras (Leica Microsystems). Comparison of the VTC phenotype of $\mathrm{Boc}^{-/-}$animals was performed using central sections taken at the level of the optic nerve. Care was taken to compare equivalent sections for each of the stages analyzed and to provide in each one of the relevant figures an image of either the second or third section through the optic nerve for either WT or mutant animals. The limit of the VTC extension was defined for each stage using Zic2 immunostaining or hybridization on serial sections 
from WT embryos. The extent of positive staining was used to draw a mask (e.g., see Figs. $4 A, 8 A$ ). The mask was then reported on the equivalent mutant section as shown in Figures $4 B$ and $8 B$ and used to compare and quantify labeling in the two regions. The number of $\mathrm{Zic2}{ }^{+}$, Islet $2^{+}$, and Brn $3 \mathrm{~b}^{+}$cells was determined by counting positive nuclei in the VTC from four central sections of both eyes for each one of the embryos analyzed. A minimum of four or five embryos was analyzed in each case. The ipsilateral index was calculated as described by dividing the fluorescent intensity in the ipsilateral optic tract by the sum of the fluorescent intensity in both tracts (Erskine et al., 2011). Distribution of green and red fluorescent pixels in the dLGN was determined in confocal images using a LEICA TCS SP-5, taking care of comparing sections at the same anteroposterior axial level. Quantitative analysis of ipsilateral projections was performed using Image J (National Institutes of Health). Differences between calculated averages were considered significant as follows: ${ }^{\star} p \leq$ $0.05,{ }^{* *} p<0.01$, and ${ }^{* * *} p<0.001$ (Student's $t$ test).

\section{Results}

The ipsilateral projection is reduced in the absence of Boc

Boc is a cell surface glycoprotein that contains immunoglobulin and fibronectin domains. Boc, the related Cdon, and their Drosophila counterparts iHog and Boi bind Shh and can also interact with the Hh receptor Patched (Ptch), indicating that they can function as coreceptors in Hh signaling (for review, see SánchezArrones et al., 2012). Boc has an established function in axon guidance (Connor et al., 2005; Okada et al., 2006), and in its absence Shh-sensitive commissural axons are misrouted (Okada et al., 2006). In the visual system, Boc is expressed in iRGCs, whereas its ligand Shh localizes to the midline preoptic region and is also secreted by the cRGCs (Trousse et al., 2001; SánchezCamacho and Bovolenta, 2008). This distribution, together with functional experiments and the observation that $\mathrm{Boc}^{-1-}$ embryos have a reduced ipsilateral component, led to the idea that Boc/ Shh signaling could determine the laterality of RGC axons, functioning in parallel to EphB1/ephrinB2 signaling (Fabre et al., 2010), an established mechanism for the sorting of iRGC axons at the optic chiasm (Williams et al., 2003).

Using complete unilateral DiI tracing of visual axons, we have confirmed that, in the absence of $B o c$, the ipsilateral projection is reduced at embryonic (Fig. $1 A, B$ ) and postnatal stages in both the optic tract (Fig. 1C,D) and dLGN (Fig. $1 E, F^{\prime}$ ), in which the amount of innervation appeared comparatively less abundant than that observed in the optic tract at the same age, suggesting a possible slower growth of the mutant axons. An unusual accumulation of growth cones in both the chiasm (not shown) and the initial portion of the ipsilateral tract (Fig. $1 G, H$ ) provided further support to this idea. Compared with WT, the reduction of fiber in the mutant ipsilateral tract was estimated to be between 40 and $45 \%$, according to the analysis of the ipsilateral index (Fig. 1I), a semiquantitative method that compares the relative fluorescence in the ipsilateral optic tract to the sum of fluorescence intensity in both tracts (Erskine et al., 2011).

\section{Boc acts downstream of $\mathrm{Zic} 2$ but does not suffice to activate the ipsilateral program}

$B o c$ is expressed in the VTC, with higher intensity in the Zic2positive cells (Sánchez-Camacho and Bovolenta, 2008; Fabre et al., 2010) and in the ciliary marginal zone (CMZ) (Fig. 2A-C). In $B o c$ absence, ipsilateral projections are reduced, suggesting that $B o c$, as EphB1, could act downstream of Zic2. To address this possibility, we analyzed $B o c$ distribution in $Z i c 2^{k d / k d}$ and Foxd $1^{-1-}$ mice, as Foxd1 has been shown to act upstream of Zic2 in the specification of the ipsilateral program (Carreres et al., 2011). Indeed, Boc was absent from the VTC of $Z i c 2^{k d / k d}$ (Fig. 2E) and Foxd1 $1^{-1-}$ (data not shown) embryos but still observed in the
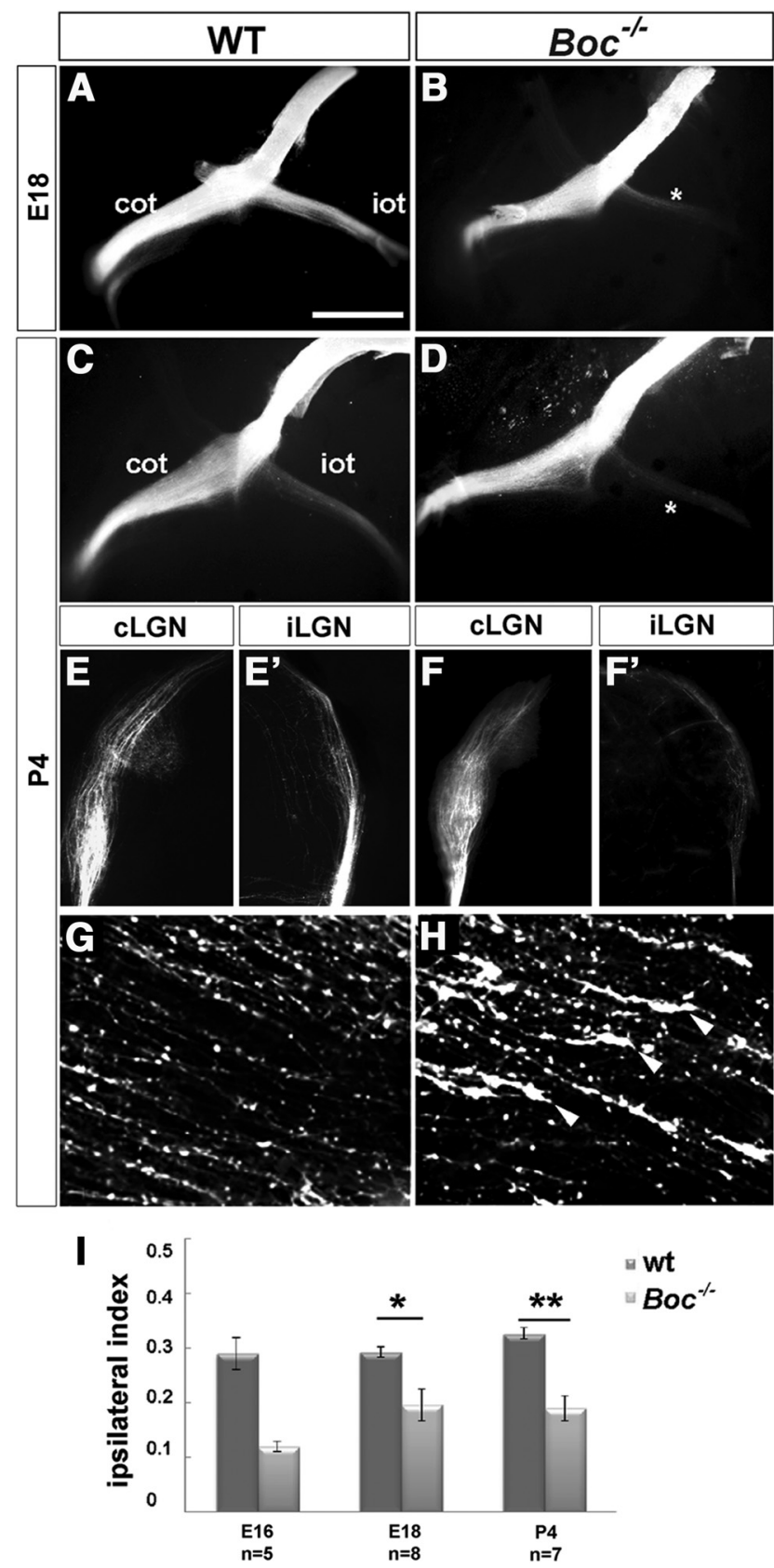

Figure 1. $B \mathrm{BC}^{-/-}$mice present a reduction of uncrossed retinal projections. $\boldsymbol{A}-\boldsymbol{H}$, Ventral views of the intact brains $(\boldsymbol{A}-\boldsymbol{D})$ and frontal $\left(\boldsymbol{E}-\boldsymbol{F}^{\prime}\right)$ or horizontal $(\boldsymbol{G}, \boldsymbol{H})$ vibratome sections through the contralateral and ipsilateral dLGN $\left(\boldsymbol{E}-\boldsymbol{F}^{\prime}\right)$ and optic chiasm $(\boldsymbol{G}, \boldsymbol{H})$ from E18 and P4 WT and $\mathrm{BOC}^{-1-}$ animals (as indicated in the panels) with unilateral Dil filling of the optic disk to visualize visual fiber trajectory. There is strong reduction of projecting fibers in the ipsilateral lateral geniculate nucleus (iLGN) of the mutants. *Ipsilateral reduction. $\boldsymbol{F}$, Arrowheads indicate growth cones in the initial portion of the mutant ipsilateral optic tract. $I$, The graph compares the values of the ipsilateral index in WT and $\mathrm{BOC}^{-1-}$ mice at embryonic and postnatal stages. The number of analyzed animals is indicated in the graph for each stage. ${ }^{*} p<0.05$ (Student's unpaired $t$ test). ${ }^{* *} p<0.01$ (Student's unpaired $t$ test). cLGN, Contralateral lateral geniculate nucleus; cot, contralateral optic chiasm; iot, ipsilateral optic tract. Scale bars: $\boldsymbol{A}-\boldsymbol{D}, 1000 \mu \mathrm{m} ; \boldsymbol{E}$, $\boldsymbol{F}, 500 \mu \mathrm{m}$.

CMZ, where its homolog Cdon is also expressed (Fig. 2D,F). These data support that Boc expression is downstream of Zic2 and/or Foxd1.

EphB1, the main Zic2 target involved in determining iRGC behavior at the midline, is sufficient to force contralateral axons into an ipsilateral trajectory (Petros et al., 2009). If Boc acts in a 


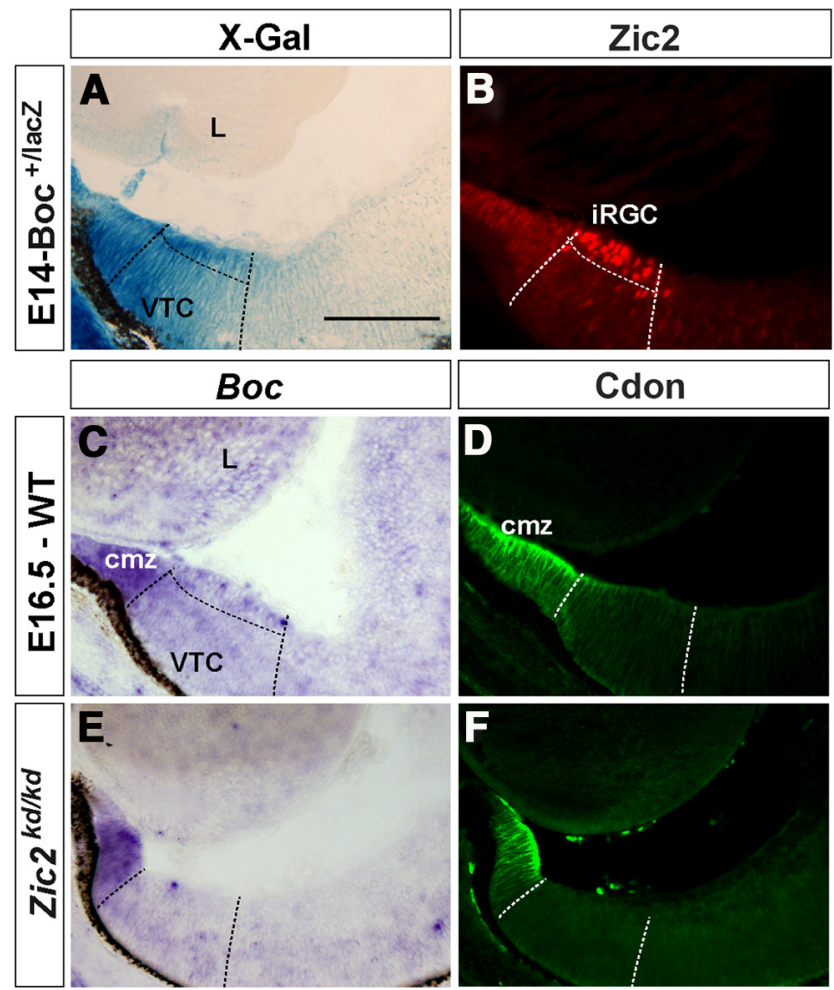

Figure 2. Boc expression is downregulated in the VTC of Zic $2^{k d / k d}$ embryos. Frontal cryostat sections from E14.5 Boc ${ }^{+/ l a c Z}$ and 16.5 WT and Zic ${ }^{k d / k d}$ central retinas reacted with with X-gal histochemistry, hybridized with probes for Boc or immunostained with antibodies against Zic2 and the related Cdon. $A, B$, The specific expression of Boc in the VTC is particularly abundant in the Zic2-positive domain. $\mathbf{C}-\boldsymbol{F}$, Boc expression is absent in Zic2 ${ }^{\mathrm{kd} / \mathrm{kd}}$ embryos but maintained in the CMZ where Cdon is also localized. cmz, Ciliary marginal zone; L, lens. Scale bar, $200 \mu \mathrm{m}$.

similar manner, ectopic expression of Boc should be sufficient to induce an ipsilateral behavior in cRGC, as observed when EphB1, Zic2, or Foxd1 is overexpressed in cRGCs (Garcia-Frigola et al., 2008; Lee et al., 2008; Petros et al., 2009; Carreres et al., 2011). To test this possibility we compared the efficiency with which Boc, Zic2, Foxd1, or a combination of Zic2 ${ }^{+}$Boc or Foxd $1^{+}$Boc change the trajectory of cRGC axons from crossed to uncrossed, when electroporated into the eye of E13 WT embryos, which were subsequently analyzed at E18. As previously reported (GarciaFrigola et al., 2007; Sánchez-Camacho and Bovolenta, 2008), electroporations at this stage mostly targeted RGCs in central retina (Fig. 3A). When a control pCAG-GFP plasmid was expressed, the entire population of GFP-positive axons crossed the midline with very rare exceptions in which individual axons were observed in the contralateral optic nerve or ipsilateral optic tract (Fig. 3B). The vast majority of cRGCs with forced expression of Boc showed a normal crossed behavior (Fig. 3C,D), whereas a few axons consistently adopted alternative routes, either entering the contralateral optic nerve or, to a lower extent, the ipsilateral optic tract (Fig. $3 D^{\prime}, D^{\prime \prime}$ ), as reported (Fabre et al., 2010). This proportion, however, represented only a small fraction of the targeted population (Fig. $3 G$ ), in contrast to the significant amount of axons that adopt an uncrossed trajectory upon pCAG-Zic2 (Fig. $3 E, G$ ) or pCAG-Foxd1 (data not shown) forced expression. Notably, coelectroporation of Boc with either Zic2 (Fig. $3 F$ ) or Foxd1 (data not shown) did not increase the proportion of uncrossed fibers observed with Zic2 alone (Fig. 3G), strongly supporting that Boc alone is insufficient to switch the axonal laterality of already committed cRGCs, forcing them to grow ipsilaterally.
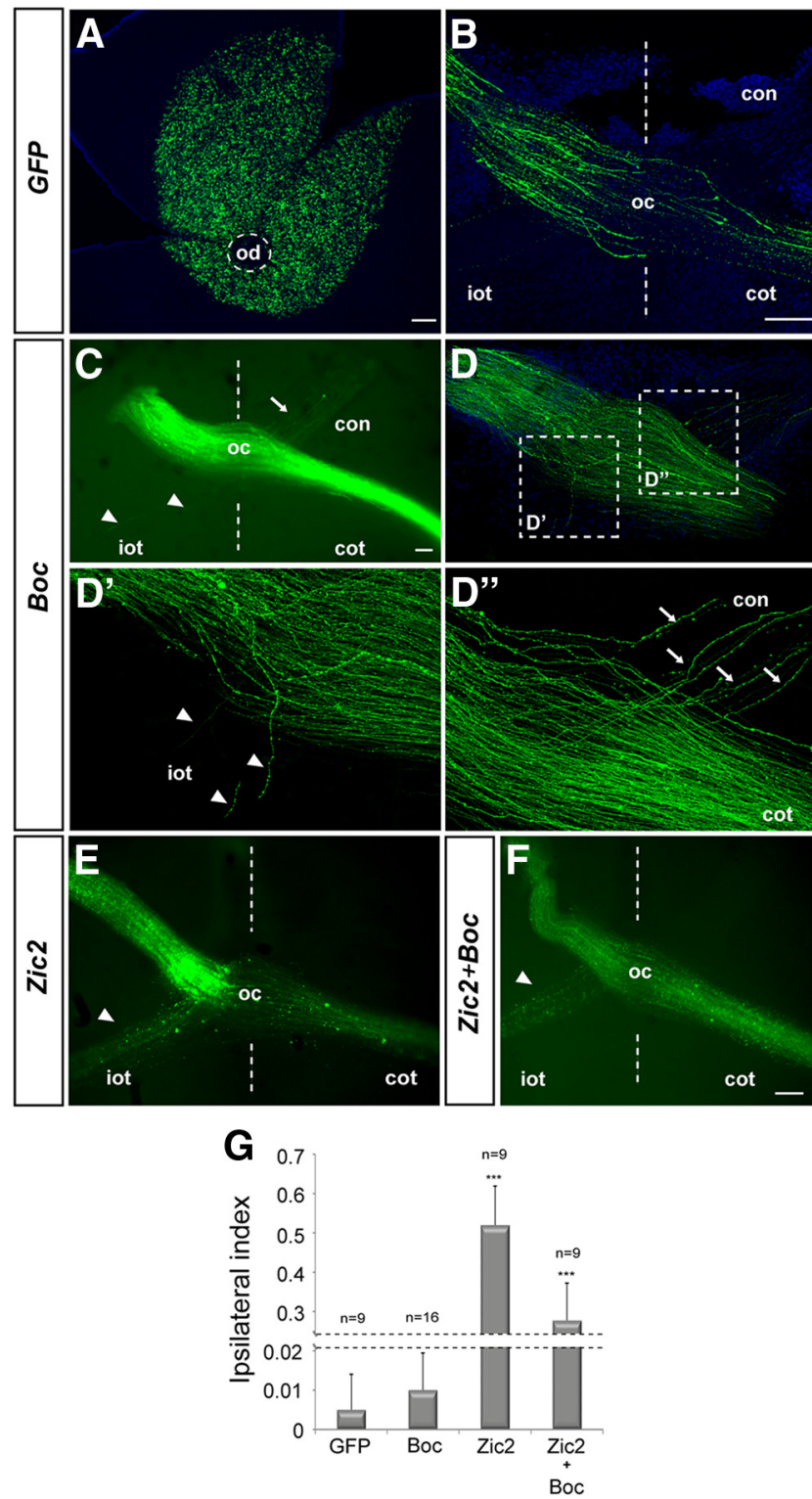

Figure 3. Boc is insufficient to activate the ipsilateral program. $\boldsymbol{A}-\boldsymbol{F}$, Confocal images of flatmounted electroporated retina $(\boldsymbol{A})$ and representative sections of the optic chiasm $(\boldsymbol{B}-\boldsymbol{F})$ from E18 embryos electroporated at E13 with a plasmid expressing GFP alone $(\boldsymbol{A}, \boldsymbol{B})$, or GFP with $B \circ(\boldsymbol{C}, \boldsymbol{D})$, Zic2 $(\boldsymbol{E})$, or Zic2 and Boc $(\boldsymbol{F})$. Electroporations mostly targeted the central retina $(\boldsymbol{A})$. $\boldsymbol{D}^{\prime}, \boldsymbol{D}^{\prime}$, Highmagnification views of the areas boxed in $\boldsymbol{D}$. In embryos electroporated with $B o c$, most axons $(\boldsymbol{C}, \boldsymbol{D})$ cross the midline (dotted lines), whereas a few axons grow into the ipsilateral optic tract $\left(\boldsymbol{D}_{\mathbf{D}} \boldsymbol{D}^{\prime}\right.$, arrowheads) and in larger numbers in the contralateral optic nerve ( $\boldsymbol{D}^{\prime \prime}$, arrows). $\mathbf{G}$, The graph compares the values of the ipsilateral index in embryos electroporated with the different constructs. The number of analyzed animals is indicated on top of each bar. ${ }^{* *} p<0.001$, compared with GFP (Student's unpaired ttest). od, Optic disc; con, contralateral opticnerve; oc, optic chiasm; iot, ipsilateral optic tract; cot, contralateral optic tract. Scale bar, $100 \mu \mathrm{m}$.

\section{Boc is required to maintain an appropriate number of $\mathrm{Zic}^{+}$ iRGCs in the VTC}

Together, our data indicate that Boc inactivation affects only a proportion of the ipsilateral fibers and Boc alone is insufficient to induce a substantial uncrossed behavior in cRGC. We thus considered that these observations would better fit the idea that Boc/ Shh signaling is involved in iRGC specification, similarly to what has been reported for ventral neurons in the zebrafish neural tube (Bergeron et al., 2011). Shh is secreted from the adjacent cRGCs (Sánchez-Camacho and Bovolenta, 2008). This raises the possibility that, as observed during forebrain patterning (Brown et al., 
2003; Sanek et al., 2009), Shh could activate Zic2 expression in iRGC. Notably, Shh receptors, such as Gas1 (Lee et al., 2001) and Cdo (Fig. 2D), which exhibit functional redundancy with Boc in some tissues (Allen et al., 2011; Bae et al., 2011), are coexpressed in the CMZ, but only Boc is found in the VTC (Fig. 2A) (SánchezCamacho and Bovolenta, 2008; Fabre et al., 2010). Therefore, the loss of Boc could be expected to have a significant impact on Shh reception by the iRGC.

To investigate this possibility, we compared the distribution of Zic2 mRNA and protein and of its direct downstream target Sert (Garcia-Frigola and Herrera, 2010) in WT and $B o c^{-1-}$ retinas from E16, E18, and newborn animals (Fig. 4). Zic2 expression starts to wane at E17, but it is still detectable at postnatal stages in WT animals (Fig. 4A,E,I). Quantification of Zic2 ${ }^{+}$cells in the VTC revealed no significant difference between WT and $B o c^{-/-}$ E16 embryos (Fig. $4 \mathrm{M}$ ), although in $\mathrm{Boc}^{-/-}$embryos positive cells appeared clustered toward the CMZ (Fig. 4B). This clustering was more evident at later embryonic and early postnatal stages, when Zic2 and Sert-positive cells were also significantly decreased compared with WT (Fig. 4E-M). This decrease could be a consequence of cell death or of a change in cell proliferation. However, no TUNEL-positive cells were observed in this region between E18 and P1 in WT or in $B o c^{-1-}$ retinas (not shown). Similarly, there was no difference in the number of phosphohistone H3-positive cells between WT and mutants retinas, suggesting that changes in cell death and proliferation are unlikely causes of the observed phenotype.

\section{Boc is required to restrain Islet2/Shh expression within the VTC}

To confirm that decreased Zic2 staining did not reflect cell loss, we stained retinal sections from WT and $\mathrm{Boc}^{-/-}$embryonic and postnatal animals with antibodies against Brn3b, which labels most RGCs, including those of the VTC (Quina et al., 2005). The total number of RGCs in the VTC of embryonic and newborn mice was similar in WT and $B o c$ mutants (Fig. $\left.5 A, A^{\prime}, E, E^{\prime}, I, I^{\prime}, P\right)$.

When Islet2 is genetically inactivated, an abnormally high number of $\mathrm{Zic} 2{ }^{+}$cells accumulates in the VTC with a consequent increase of the ipsilateral projections, suggesting that Islet 2 represses Zic2 expression in the VTC, thereby controlling the magnitude of the uncrossed component (Pak et al., 2004). We thus reasoned that invariance of $\mathrm{Brn} 3 \mathrm{~b}^{+}$cells associated with a loss of $\mathrm{Zic} 2{ }^{+}$cells could reflect the existence of a converse regulation in which reduced Zic2 levels would favor the generation of Islet ${ }^{+}$ cells. In the VTC, Islet ${ }^{+}$cRGCs are normally generated from E17 to P1 (Drager and Olsen, 1980; Drager, 1985), intermingling with the Zic2 ${ }^{+}$cells (Fig. 5 B, F,J). Double labeling with Zic2 and Islet 2 antibodies and in situ hybridization against Islet 2 revealed that, in the $\mathrm{Boc}^{-/-}$retinas of $\mathrm{E} 18$ and $\mathrm{P} 0$ animals, the number of Islet $2^{+}$cells in the VTC was significantly increased, in parallel with the progressive decrease of $\mathrm{Zic} 2^{+}$cells (Fig. $5 F, F^{\prime}, G, G^{\prime}, J, J^{\prime}$, $\left.K, K^{\prime}, P\right)$. Consistent with this observation and the notion that $S h h$ is expressed in cRGC (Sánchez-Camacho and Bovolenta, 2008), Shh mRNA was also abnormally localized to the $B o c^{-1-}$ VTC at these ages (Fig. $5 D, D^{\prime}, H, H^{\prime}, L, L^{\prime}$ ).

Together, these data suggested that part of the Zic2 ${ }^{+}$iRGCs in the VTC are respecified as Islet $2^{+}$cRGCs. If this is the case, contralateral projections from the VTC should be increased in the mutant retinas. To verify this possibility, we retrograde labeled visual projections of E17 embryos by injecting DextranRhodamine in the optic tract of exposed brain preparations (Herrera et al., 2003). Analysis of flat-mounted retinal prepara-
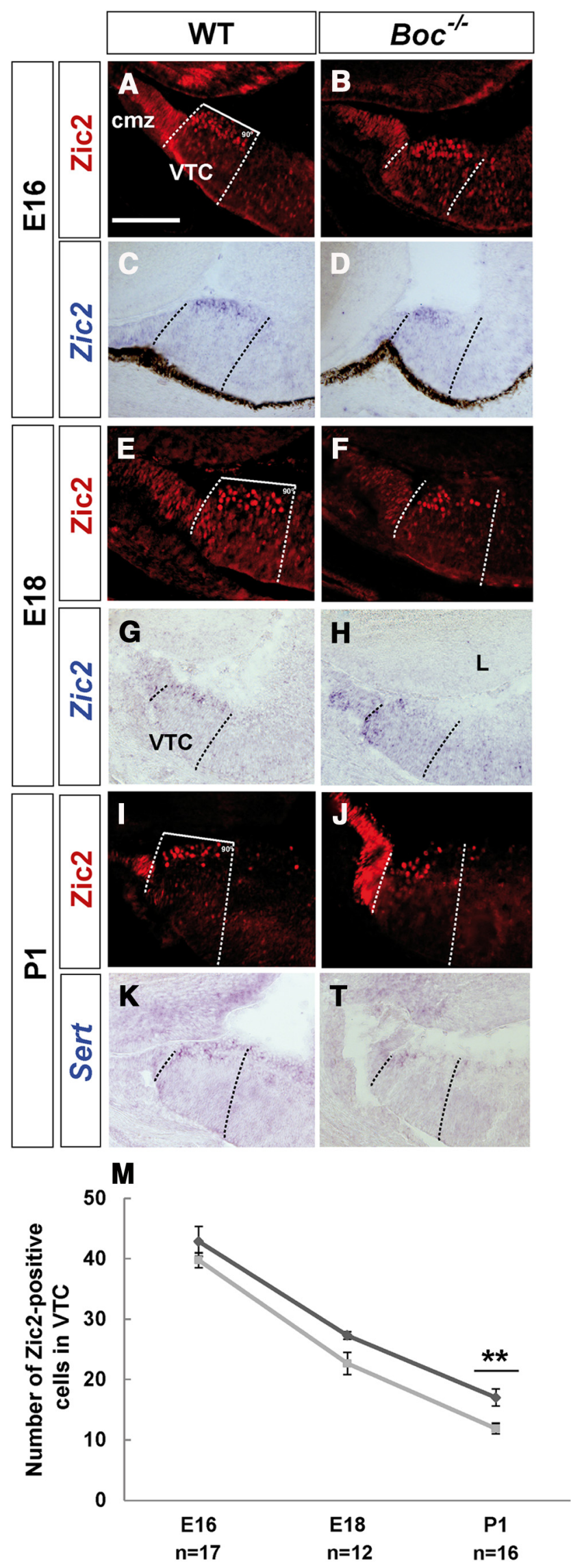

Figure 4. $\boldsymbol{A}-\boldsymbol{L}$, Boc is required to maintain the appropriate number of Zic2-positive iRGCs. Frontal cryostat sections from E16 $(\boldsymbol{A}-\boldsymbol{D}), \mathrm{E} 18(\boldsymbol{E}-\boldsymbol{H})$, and P1 $(\boldsymbol{I}-\boldsymbol{L})$ WT and Boc ${ }^{-/-}$central 
tions confirmed that in WT mice the majority of backfilled neurons localized to the ipsilateral VTC, whereas only a few backfilled cells localized to the contralateral VTC (Fig. 5M-O), as expected for this stage when cRGCs in the VTC are just beginning to form. In Boc mutants instead, there was a statistically significant reduction of backfilled cells localized to the ipsilateral VTC associated with an increase of backfilled and $\mathrm{Zic} 2{ }^{-}$cells in the contralateral VTC (Fig. 5 $M^{\prime}-O^{\prime}, Q$ ). These data support that, in the absence of $B o c$, the generation of RGCs in the VTC is shifted in favor of the cRGC type.

\section{The organization of retinal projections at the dLGN is altered in the absence of Boc}

The ipsilateral and contralateral projections from the VTC terminate in well-defined regions of the dLGN. Ipsilateral projections form a defined patch in the dorsomedial dLGN, whereas contralateral projecting VTC neurons cluster in a small region at the dorsal-most tip of the dLGN (Jaubert-Miazza et al., 2005; Rebsam et al., 2009). If $\mathrm{Zic} 2^{+}$iRGCs in the $\mathrm{Boc}^{-1-}$ VTC are indeed respecified as Islet ${ }^{+}$ cRGCs, these two fields should be respectively reduced and increased in $\mathrm{Boc}^{-/-}$animals.

To address this issue, we labeled each eye with CTBAlexaFluor dyes and analyzed the distribution of retinal projections in the dLGN at P12, P18, and P30, which collectively represent the period in which the terminal field of crossed and uncrossed projections become finally segregated (Jaubert-Miazza et al., 2005). As previously described (Jaubert-Miazza et al., 2005; Rebsam et al., 2009), ipsilateral projections (red) in P12 WT animals $(n=4)$ formed a small and defined patch in the dorsomedial dLGN surrounded by the contralateral projections (green), which occupy most of the dLGN with a small cluster at the dorsomedial tip representing cRGC projections from the VTC (Fig. $6 A-C)$. In Boc mutants instead, ipsilateral projections in the dorsomedial dLGN were visibly reduced (Fig. $6 E ; n=4$ by $32 \%$ ), whereas the dorsal cluster of contralateral axons was more intense (Fig. 6D). Notably, confocal analysis of green and red fluorescence distribution revealed a good deal of overlap between projections from the left and right eye in the dorsal dLGN (Fig. $6 D-F)$. This was confirmed by analysis of fluorescence distribution in the $z$ plane (reslice profile). In WT, ipsilateral projections were clustered in a well-defined spot of $\sim 175 \mu \mathrm{m}$ of width with a relatively homogeneous pixel distribution and a minimal overlap with crossed projections (green) from the other eye (Fig. $6 C^{\prime}$ ). In $B o c$ mutants instead, red channel fluorescence (ipsilateral) was scattered with an uneven intensity in a wider region $(\sim 400 \mu \mathrm{m})$ that extensively overlapped with the green spectrum of the crossed projections from the other eye (Fig. $6 F^{\prime}$ ). This overlap could reflect delayed segregation of ipsilateral and contralateral fibers, the presence of misrouted ipsilateral fibers as previously suggested (Fabre et al., 2010), or even contralateral sprouts on unoccupied dorsocentral dLGN neurons.

Compared with WT $(n=3)$, a smaller ipsilaterally targeted area was still observed in $\mathrm{Boc}^{-/-}$mice at P18 ( $n=3$; by 33\%; Fig. $6 G-I, J-L)$, and crossed and uncrossed projections were still intermingled (Fig. $6 I^{\prime}, L^{\prime}$ ) as confirmed by confocal analysis of red

$\leftarrow$

retinas immunostained for Zic2 or hybridized with specific probes for Zic2 and Sert as indicated in the panels. The loss of Zic 2 immunostaining is preceded by a decrease in its mRNA expression (compare $\boldsymbol{C}$ and $\boldsymbol{G}$ with $\boldsymbol{D}$ and $\boldsymbol{H}$ ). There is a progressive decrease and distal clustering of Zic2/ Sert-positive and iRGCs in the Boc ${ }^{-1-}$ VTC. $M$, The graph represents the percentage of Zic2 ${ }^{+}$ cells in the VTC of WT (dark gray line) and mutant (light gray line) animals at different stages. ${ }^{* *} p<0.01$ (Student's unpaired $t$ test). cmz, Ciliary marginal zone; L, lens. Scale bar, $200 \mu \mathrm{m}$. and green fluorescence in the $z$ plane. Peaks of red fluorescence (ipsilateral) were detected in regions that in WT are normally occupied only by crossed projections (Fig. $6 I^{\prime}, L^{\prime}$ ), including the dorsal-most region of the dLGN (Fig. 6, compare $I^{\prime} 1, L^{\prime} 1$ ), in which late-born, contralateral projecting VTC neurons originate (Rebsam et al., 2009). Green (contralateral) fluorescence was also abnormally observed in the dorsocentral $\mathrm{Boc}^{-/-} \mathrm{dLGN}$, although this was less defined (Fig. $\left.6 I^{\prime}, L^{\prime}\right)$. Analysis of P30 animals $(n=4)$, when activity-dependent segregation is fully accomplished, confirmed that, in the $\mathrm{Boc}^{-/-} \mathrm{dLGN}$, the ipsilateral field was reduced in medial areas (Fig. $7 A, B, E, F$ ), whereas it appeared more disperse and intermingled with contralateral projections in caudal areas compared with WT animals (Fig. 7, compare $C, D, G, H$ and their respective reslice profiles). Nevertheless, the overall area occupied by ipsilateral axons was reduced of $\sim 36.5 \%$ in the Boc mutants. By contrast, the cluster of cRGCs terminals at the dorsal tip of the dLGN was more evident than in WT, as better appreciated in the respective reslice profiles (Fig. $7 A, C, E, G$, reslices 1).

Together, these data suggest that, in $\mathrm{Boc}^{-1-}$ mice, the ipsilateral domain of the dLGN is only partially innervated and further receives few fibers from the contralateral eye, which could represent abnormally sorted uncrossed projections (Fabre et al., 2010). Most notably, and supporting a shift in identity of RGCs in the VTC, $\mathrm{Boc}^{-1-}$ animals present an increased clustering of fibers in the region where late-born VTC cRGCs project.

\section{A feedback regulatory loop between Zic2 and Shh signaling in the VTC}

Together, the above data demonstrate that Boc is required for the generation of an appropriate proportion of iRGCs and consequently for the proper targeting of visual fibers at the dLGN. Boc acts as a high-affinity receptor for Shh, modulating its diffusion (Sánchez-Arrones et al., 2012). In other CNS regions, Zic2 expression seems to depend upon Shh signaling (Brown et al., 2003; Hayhurst et al., 2008; Sanek et al., 2009), and Zic2, in turn, functions as a negative modulator of Shh-induced gene expression (Sanek et al., 2009). We thus postulated that, in the absence of Boc, which can increase cell sensitivity to Shh (Bergeron et al., 2011), the Shh pathway may be insufficiently activated in the VTC to sustain Zic2 expression, the progressive loss of which would favor the generation of more late-born Islet $2^{+}$cRGCs. Consistent with this hypothesis, the observed decrease in Zic2 immunostaining at E18 was preceded by a reduction of Zic2 mRNA levels in the $\mathrm{Boc}^{-/-}$VTC already at E16 (Fig. 4C, D, G,H). Conversely, expression of Islet2 and Shh was expanded in the VTC of Zic2 ${ }^{k d / k d}$ and Foxd $1^{-/-}$embryos (Fig. 8A-I).

The existence of a feedback regulatory loop between Zic2 and Shh signaling, similar to that observed in forebrain patterning (Sanek et al., 2009), was further supported by the ectopic expression of Shh in the VTC of WT E13 embryos by means of in utero electroporation that led to the strong reduction of Zic2 in transduced and adjacent cells analyzed $2 \mathrm{~d}$ later (Fig. 8J-K'). In addition, qPCR analysis of Shh and Boc mRNA levels $24 \mathrm{~h}$ after ectopic expression of Zic2 in the central retina revealed a significant reduction of Shh expression and a concomitant significant increase in $B o c$ expression (Fig. $8 L$ ), consistent with what observed in Zic $2^{k d / k d}$ mice.

\section{Discussion}

The mouse retina comprises two distinct RGC populations, when considering their axon behavior at the chiasm. A small cohort of neurons generated in the VTC projects to the ipsilateral side of the brain directed by postmitotic Zic2 expression (Herrera et al., 


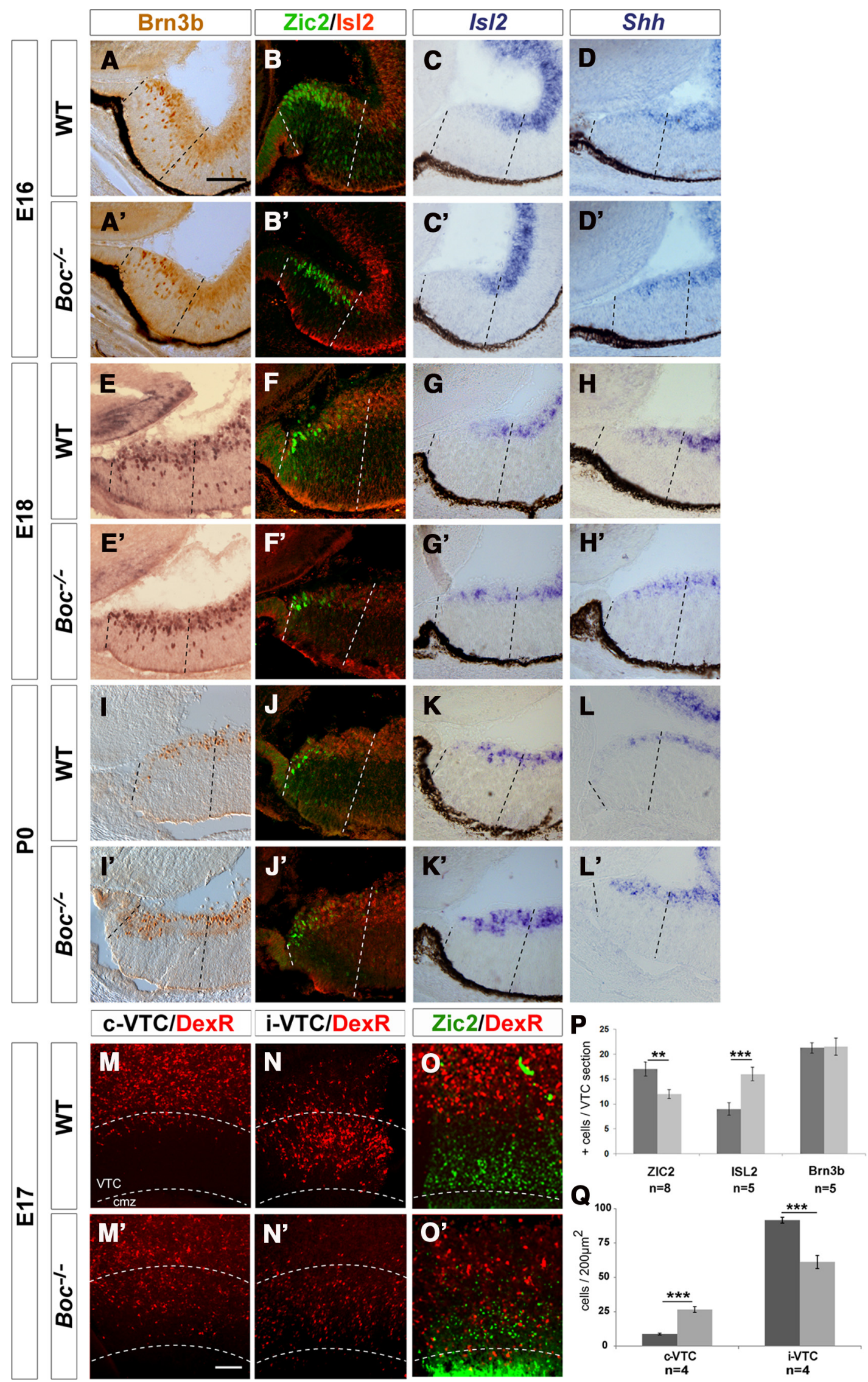

Figure 5. $\boldsymbol{A}-\boldsymbol{L}^{\prime}$, Boc is required to restrain Islet2/Shh expression within the VTC. Frontal cryostat sections from E16 $\left(\boldsymbol{A}-\boldsymbol{D}^{\prime}\right)$, E18 $\left(\boldsymbol{E}-\boldsymbol{H}^{\prime}\right)$, and P0 $\left(\boldsymbol{I}-\boldsymbol{L}^{\prime}\right)$ WT and Boc ${ }^{-I-}$ central retinas immunostained for Brn3b, double-stained for Zic2 (green) and Islet2 (red), or hybridized with specific probes for Is/2 and Shh, as indicated in the panels. The increase in Islet2 ${ }^{+}$cells parallels the decrease in Zic2 ${ }^{+}$cells in Boc ${ }^{-1-}$ tissue. There is a correspondent increase in /slet2 and Shh expression in the mutants starting from E18. Dashed lines delimit the (Figure legend continues.) 


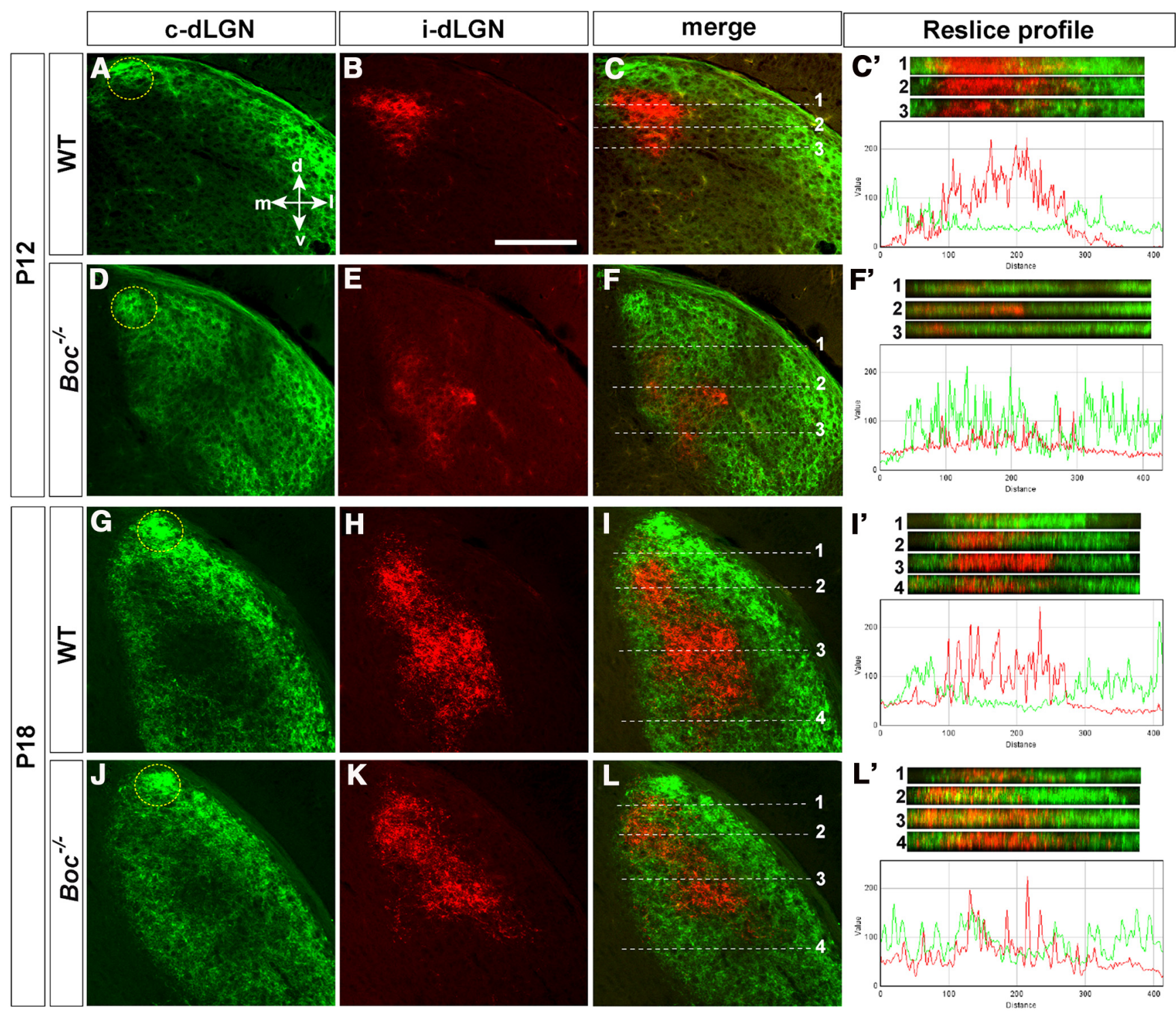

Figure 6. Organization of the retino-geniculate projections in postnatal $B \mathrm{CC}^{-1-}$ mice. Confocal analysis of frontal sections through the dLGN of P12 and P18 WT and $B o C^{-/-}$mice (as indicated in the panels) after whole-eye anterograde tracing with green and red fluorescent dyes. $\boldsymbol{C}^{\prime}, \boldsymbol{F}^{\prime}, \boldsymbol{I}^{\prime}, \boldsymbol{L}^{\prime}$, Reslice profiles taken at the levels indicated in $\mathbf{C}, \boldsymbol{F}, \boldsymbol{I}$, and $\boldsymbol{L}$, respectively. The accompanying graphs represent the spectra of red (ipsilateral) and green (contralateral) channels of reslice $2\left(\boldsymbol{C}^{\prime}, \boldsymbol{F}^{\prime}\right)$ and reslice $3\left(\boldsymbol{I}^{\prime}, \boldsymbol{L}^{\prime}\right)$, respectively. In WT, the ipsilateral projection (red) is clustered in the dorsocentral dLGN surrounded by contralateral terminations (green). In $\mathrm{Boc}^{-1-}$, ipsilateral fibers are reduced in this region. There is increased clustering of fiber in the dorsomedial tip (area circled with dotted lines) of dLGN where late-born cRGCs of the VTC project. $d$, Dorsal; $m$, medial; I, lateral; v, ventral. Scale bar: $A-L, 250 \mu \mathrm{m}$.

2003), whereas a large RGC population specified throughout the retina projects to the contralateral side of the brain. The amount of Zic2 ${ }^{+}$iRGCs generated in the VTC is strongly limited by the expression of Islet2, a transcription factor expressed by many cRGCs. Indeed, genetic inactivation of Islet2 leads to an overproduction of Zic2 ${ }^{+}$neurons within the VTC, which fully behave as

$\leftarrow$

(Figure legend continued.) VTC. $\mathbf{M}-\mathbf{O}^{\prime}$, Low-power views of flat-mounted preparations of the ipsilateral and contralateral retinas from E17 embryos subjected to unilateral retrograde labeling from the optic tract, double-labeled with antibodies against Zic2 $\left(\mathbf{0}, \mathbf{0}^{\prime}\right)$. In WT, the majority of backfilled neurons localized to the ipsilateral VTC (the VTC area is marked with dotted lines), whereas only few RGCs were found in the contralateral VTC. In $B \mathrm{Cc}^{-1-}$ VTC, this proportion is shifted and there are numerous Zic ${ }^{+}$backfilled cells in the $\operatorname{CVTC}\left(\boldsymbol{O}^{\prime}\right) . \boldsymbol{P}, \mathbf{Q}$, The histograms represent the amount of Zic $2^{+}$, Islet2 ${ }^{+}$, or Brn $3 b^{+}$cells in $\mathrm{PO}(\boldsymbol{P})$ and the amount of backfilled cells present in the ipsilateral and contralateral retinas of E17 (Q) , and WT (dark gray bars) and $B c^{-1-}$ (light gray bars) VTC. ${ }^{* *} p<0.01$ (Student's unpaired $t$ test). ${ }^{* * *} p<$ 0.001 (Student's unpaired $t$ test). cmz, Ciliary marginal zone. Scale bar, $100 \mu \mathrm{m}$. ipsilateral projecting neurons (Pak et al., 2004). Our study now complements these observations and identifies a regulatory loop between Zic2 and Boc-mediated Shh signaling as an important mechanism that limits the generation of Islet $2^{+}$cells in the VTC, thus maintaining the appropriate number of iRGCs in the mouse retina. Disruption of this regulatory loop shifts RGC production in the VTC toward a contralateral projecting fate, with consequent alterations in the retinotopic organization at the dLGN.

Our conclusions stem from the observation that in $\mathrm{Boc}^{-1-}$ mice the ipsilateral projection is reduced, without apparent loss of the overall number of RGCs in the VTC. Analysis of the retinotopic distribution in the $\mathrm{Boc}^{-/-}$dLGN showed that part of the fibers originating from the ipsilateral eye target an area normally receiving contralateral projections, including those from lateborn Islet $2^{+}$cells of the VTC. Consistent with this observation, $\mathrm{Zic} 2^{+}$cells in the $\mathrm{Boc}^{-/-}$VTC, although present in normal numbers at embryonic stages, are diminished postnatally, whereas 
Islet ${ }^{+}$cells are increased, indicating a shift in identity of part of the RGCs in the VTC.

A previous study explained the reduction of ipsilateral fibers in $\mathrm{Boc}^{-/-} \mathrm{em}-$ bryos as a failure of axons to remain uncrossed, proposing that Boc normally mediates repulsive guidance information from midline-derived Shh. This hypothesis is based on tracing analysis at embryonic stages, turning assays in Boc-expressing RGCs and $B o c$ overexpression studies similar to those presented here (Fabre et al., 2010). Our results now provide additional and complementary explanations for the ipsilateral visual fiber reduction in Boc mutants. Notably, however, our finding suggests that the influence of Boc on iRGC uncrossing behavior is not robust and likely needs to be fostered by other molecular determinants of chiasmatic fiber sorting (Petros et al., 2008). Although we observed a modest increase in the total number of axons that aberrantly project ipsilaterally upon $B o c$ overexpression as shown in (Fabre et al., 2010), this change in axonal laterality is not substantial when analyzed in the context of the total number of cells that overexpress Boc or compared with the effect of gain-of-Zic2 function. Furthermore, in Boc mutants, postnatal retinotopic organization at the dLGN is different from that reported for other mouse mutants with reduced ipsilateral projections and increased fiber decussation, such as the EphB1 ${ }^{-/-}$and $\mathrm{Tyr}^{c-2 J / c-2 J}$ (albino) mice, in which the cohort of misprojecting fibers terminates in a patch well segregated from the surrounding projections (Rebsam et al., 2009; Rebsam et al., 2012). In the EphB1 ${ }^{-/-}$mutants, the patch localizes within the ipsilateral domain, whereas in albinos it lies close to the region where late-born VTC neurons project. These differences have been interpreted as a differential retention of ipsilateral identity in misrouted neurons (Rebsam et al., 2012). Indeed, in EphB1 ${ }^{-/-}$mutants, Zic2 is still expressed in misprojecting neurons (E.H., unpublished observations), consistent with the reported regulation of EphB1 by Zic2 (Garcia-Frigola et al., 2008; Lee et al., 2008). In albino mice instead, there are less $\mathrm{Zic} 2^{+}$cells in the VTC, although there is no parallel increase in the expression of crossed projections markers, suggesting abnormal specification (Rebsam et al., 2012). In $\mathrm{Boc}^{-/-}$mice, misrouted fibers from the ipsilateral eye invade the field destined to contralateral projections, especially the zone of late-born VTC neurons as in albinos. There is, however, a fundamental difference: misrouted fibers intermingled with the surrounding projections, reflecting that a proportion of VTC neurons shifted to full contralateral identity, as also supported by the increased in retrograde-labeled and Islet $2 / \mathrm{Shh}^{+}$cells. Consistent with abnormal sorting at the chiasm (Fabre et al., 2010), sparse
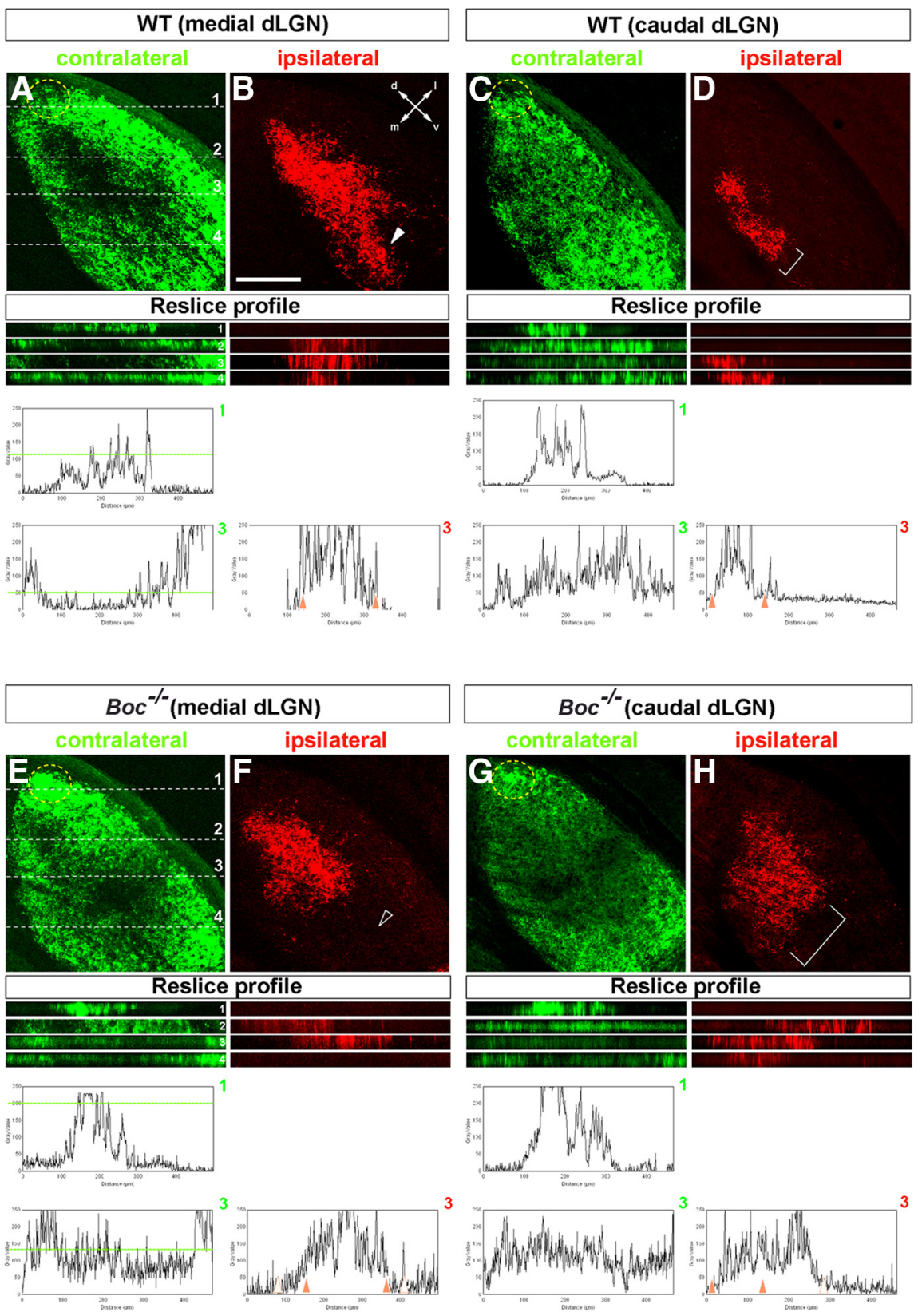

Figure 7. Organization of the retino-geniculate projections in adult $\mathrm{Boc}^{-1-}$ mice. The images show confocal analysis of frontal sections through different axial levels of the $\mathrm{dLGN}$ of P3O WT and $\mathrm{BOC}^{-1-}$ mice after whole-eye anterograde tracing with green and red accompanying graphs represent the spectra of red (ipsilateral) and green (contralateral) channels of the reslices as indicated in the figure. d, Dorsal; m, medial; I, lateral; v, ventral. Scale bar, $250 \mu \mathrm{m}$.

terminations from the contralateral eye localized to the $\mathrm{Boc}^{-/-}$dorsomedial ipsilateral field, particularly in the caudal dLGN. These mistargeted fibers may alternatively represent axons that have missed midline guidance information because they grow at lower pace, as suggested by the abnormal growth cone accumulation in the chiasm and ipsilateral tract and the particularly reduced innervation of the mutant dLGN at early stages. As an additional possibility, they could represent contralateral sprouts on unoccupied dorsocentral dLGN neurons.

Searching for the relationship between $B o c$ and Zic2, we showed that in, Zic2 ${ }^{-/-}$and FoxD1 $1^{-/-}$embryos, Islet2 and Shh expression is increased, whereas Boc mRNA is decreased or absent. This supports the proposed existence of a cross-regulatory 

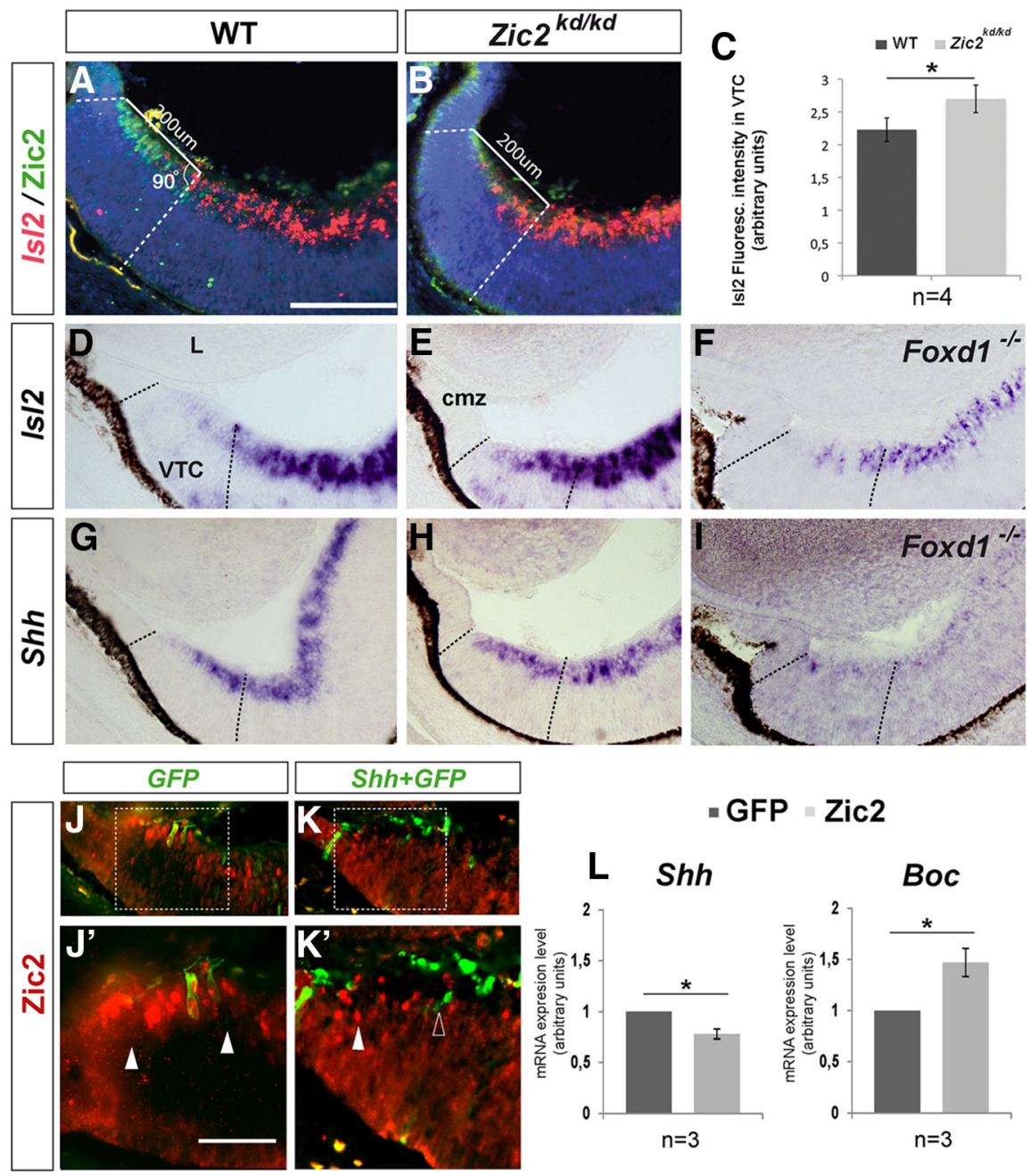

GFP $=$ Zic2

Figure 8. A feedback regulatory loop between Zic2 and Shh signaling in the VTC. $A, B, D, E-I$, Frontal cryostat sections from E16 WT $(\boldsymbol{A}, \boldsymbol{D}, \boldsymbol{G}), Z i{ }^{\mathrm{kd} / / k d}(\boldsymbol{B}, \boldsymbol{E}, \boldsymbol{H})$, and Foxd $1^{-1-}(\boldsymbol{F}, \boldsymbol{I})$ central retinal sections hybridized with probes for Islet2 $(\boldsymbol{A}, \boldsymbol{B}, \boldsymbol{D}-\boldsymbol{F})$ and Shh $(\mathbf{G}-\boldsymbol{I})$ and immunostained with antibodies against Zic2 $(\boldsymbol{A}, \boldsymbol{B})$. WT embryos are Zic ${ }^{k d / k d}$ littermates. Littermates from Foxd $1^{-/-}$ line are not shown as they were no different from those shown in $\boldsymbol{D}$ and $\mathbf{G}$. $\boldsymbol{C}$, The histogram represents the increment of Islet $2^{+}$ fluorescence in the Zic ${ }^{k d / k d}$ VTC compared with WT. ${ }^{*} p<0.05$ (Student's unpaired $t$ test). $J-\boldsymbol{K}^{\prime}$, Control GFP $\left(\boldsymbol{J}, \boldsymbol{J}^{\prime}\right)$ or Shh::GFP $(\boldsymbol{K}$, $\boldsymbol{K}^{\prime}$ ) electroporated VTC from E15 WT embryos immunostained with antibodies against Zic2 (red). There is an absence of Zic2 staining in the region where Shh is ectopically expressed, whereas Zic2 staining is still present in GFP-positive controls (solid and empty arrowheads in $\boldsymbol{J}^{\prime}-\boldsymbol{K}^{\prime}$ point to Zic2 + and - regions, respectively). $L$, qPCR analysis of the levels of Shh and Boc expression after ex utero electroporation of Zic2 in the central retina of E13 WT embryos. Tissue was collected and analyzed $24 \mathrm{~h}$ later. Analysis was performed on pools of eight different retinas for each sample, and experiments were repeated three times. Data were analyzed with the Mann-Whitney test: ${ }^{*} p<0.05$. cmz, Ciliary marginal zone; L, lens. Scale bars: $\boldsymbol{A}-\mathbf{I}, 200 \mu \mathrm{m} ; \boldsymbol{J}-\boldsymbol{K}^{\prime}, 100 \mu \mathrm{m}$.

repression between Zic2 and Islet2 in the VTC (Pak et al., 2004) and indicates that Boc acts downstream of Zic2. Zic2, a member of the Gli family of zinc-finger transcription factors, shares with Gli similar consensus binding sites on the DNA (Aruga, 2004), which, notably, are repetitively present in highly conserved noncoding regions of the Boc locus in different mammalian species (unpublished observations), suggesting a possible direct regulation. Furthermore, Boc, although important for mutual regulation between iRGC and cRGC in the VTC, is not essential for the onset of Zic2 expression, as this is normally initiated in Boc mutants but subsequently retained only in a subset of neurons. This normal initiation might be in apparent contradiction with the decreased ipsilateral projection already observed at E16. However, in the absence of Boc, initial Zic2 expression might reach levels insufficient to trigger a full ipsilateral behavior and support fiber extension at a normal speed, as suggested by the increased

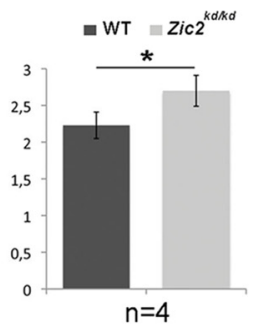

number of growth cones in the chiasm and optic tract. Although we have found no differences in proliferation or apoptosis between WT and mutant retina, we cannot completely exclude that this slower growth may interfere with axon targeting, which would finally lead to cell death, contributing to the decrease of the iRGCs population.

Studies in mouse and zebrafish have proposed that activation and likely maintenance of Zic2 expression in the forebrain depend, directly or indirectly, on Shh signaling (Brown et al., 2003; Hayhurst et al., 2008; Sanek et al., 2009). Zic2, however, predominantly localizes to the dorsal CNS, where Gli repressor forms are mostly found (Stecca and Ruiz i Altaba, 2010), suggesting that Zic2 expression requires only low Shh signaling. Taking this information together with our result, we propose a model (Fig. 9) in which low levels of Shh, diffusing from the differentiating cRGC, contributes to activate $Z i c 2$ with an opposite gradient, so that high levels of Zic2 will be always found in the distalmost retina close to the CMZ, as previously described in WT embryos at the onset of iRGC generation (Herrera et al., 2003; Tian et al., 2008). Once activated, Zic2 would then regulate $B o c$ expression in the RGC and modulate cellautonomously the responsiveness to Shh signaling, similarly to the feedback circuit between the Shh pathway and homeodomain transcription factors proposed to control patterning output in the neural tube (Lek et al., 2010). Boc, Cdon, and their Drosophila counterparts have been show to titer the levels of diffusible hh ligands (Hartman et al., 2010). Thus, in the absence of Boc, Shh might diffuse a larger distance extending its gradient within the VTC (Fig. 9). As a consequence, RGCs would receive higher Shh levels, which may in turn interfere with sustained Zic2 expression. This would explain why in $\mathrm{Boc}^{-/-}$mice residual $\mathrm{Zic} 2{ }^{+}$cells are clustered close to the CMZ In this distal region, Shh levels would be sufficiently low to sustain Zic2 levels, which would then activate EphB1 and Sert expression, enabling the formation of a partial ipsilateral projection. Cross-regulation between Zic2 and Shh signaling through Boc might also explain why Boc overexpression diminishes Zic2induced uncrossed behavior in cRGC. Indeed, Boc presence in the Shh-expressing cRGCs may trap the morphogen, increasing the levels of the signaling effector Gli1, which could compete with Zic2 for DNA binding sites, finally reducing Zic2 activity.

Differential spatiotemporal expression of Shh target genes is highly dependent on both the levels and duration of cell exposure to Shh (Dessaud et al., 2007; Balaskas et al., 2012). The floor plate cells that, as cRGCs, secrete and respond to Shh, are patterned by high and transient Shh signaling (Ribes et al., 2010). In Boc absence, increased Shh diffusion in the VTC might shift cells toward 
the cRGC program, including the onset of Islet 2 and Shh expression itself, which is known to regulate $\mathrm{cRGC}$ specification and differentiation (Esteve and Bovolenta, 2006). In a feedback loop, Shh will further repress Zic2 expression as observed upon ectopic expression of Shh in the VTC and previously reported for other Zic transcription factors in zebrafish and chick embryos (Rohr et al., 1999; Aruga et al., 2002).

Recent studies have shown that Boc, Cdon, and Gas1 can substitute one another in specific contexts as demonstrated by triple genetic inactivation in mice (Allen et al., 2011; Bae et al., 2011). The colocalization of the three receptors in the CMZ, but not in the VTC, could explain why Zic2 expression is maintained in the $\mathrm{CMZ}$ but is selectively downregulated in the $\mathrm{Boc}^{-/-}$VTC. The presence of other factors may instead explain why iRGC loss in $\mathrm{Boc}^{-/-}$mutants is partial. Lrp2, a member of the low-density lipoprotein receptor family (McCarthy et al., 2002) that binds and accumulates Shh (Christ et al., 2012) is a possible example.

In conclusion, we propose that appropriate levels of Boc-mediated Shh signaling cooperate with Zic2 toward mouse iRGC specification and connectivity. In all vertebrates, committed cRGC precursors secrete Shh (Traiffort et al., 2001; Sánchez-Camacho and Bovolenta, 2008), which influences retina neurogenesis, likely in a species-specific manner (Esteve and Bovolenta, 2006). In mice, ablation of retinal Shh or of its essential signaling component Smoothened leads to an increase in RGC number, suggesting that Shh signaling limits the production of cRGCs (Wang et al., 2005; Sakagami et al., 2009). Therefore, different levels of Shh signaling activation, likely mediated by different receptors, together with mutual repression between Zic2 and Islet2, might be at the basis of iRGC and cRGC divergence (Fig. 9) and the consequent establishment of appropriate eye specific inputs to primary targets.

\section{References}

Allen BL, Song JY, Izzi L, Althaus IW, Kang JS, Charron F, Krauss RS, McMahon AP (2011) Overlapping roles and collective requirement for the coreceptors GAS1, CDO, and BOC in SHH pathway function. Dev Cell 20:775-787. CrossRef Medline

Aruga J (2004) The role of Zic genes in neural development. Mol Cell Neurosci 26:205-221. CrossRef Medline

Aruga J, Tohmonda T, Homma S, Mikoshiba K (2002) Zicl promotes the expansion of dorsal neural progenitors in spinal cord by inhibiting neuronal differentiation. Dev Biol 244:329-341. CrossRef Medline

Bae GU, Domené S, Roessler E, Schachter K, Kang JS, Muenke M, Krauss RS (2011) Mutations in CDON, encoding a hedgehog receptor, result in holoprosencephaly and defective interactions with other hedgehog receptors. Am J Hum Genet 89:231-240. CrossRef Medline

Balaskas N, Ribeiro A, Panovska J, Dessaud E, Sasai N, Page KM, Briscoe J, Ribes V (2012) Gene regulatory logic for reading the Sonic Hedgehog signaling gradient in the vertebrate neural tube. Cell 148:273-284. CrossRef Medline

Beccari L, Conte I, Cisneros E, Bovolenta P (2012) Sox2-mediated differential activation of Six 3.2 contributes to forebrain patterning. Development 139:151-164. CrossRef Medline

Bergeron SA, Tyurina OV, Miller E, Bagas A, Karlstrom RO (2011) Brother of cdo (umleitung) is cell-autonomously required for Hedgehog-mediated ventral CNS patterning in the zebrafish. Development 138:75-85. CrossRef Medline

Brown LY, Kottmann AH, Brown S (2003) Immunolocalization of Zic2 expression in the developing mouse forebrain. Gene Expr Patterns 3:361367. CrossRef Medline

Carreres MI, Escalante A, Murillo B, Chauvin G, Gaspar P, Vegar C, Herrera E (2011) Transcription factor Foxd1 is required for the specification of the temporal retina in mammals. J Neurosci 31:5673-5681. CrossRef Medline

Christ A, Christa A, Kur E, Lioubinski O, Bachmann S, Willnow TE, Hammes A (2012) LRP2 is an auxiliary SHH receptor required to condition the forebrain ventral midline for inductive signals. Dev Cell 22:268-278. CrossRef Medline

Connor RM, Allen CL, Devine CA, Claxton C, Key B (2005) BOC, brother of $\mathrm{CDO}$, is a dorsoventral axon-guidance molecule in the embryonic vertebrate brain. J Comp Neurol 485:32-42. CrossRef Medline

Dessaud E, Yang LL, Hill K, Cox B, Ulloa F, Ribeiro A, Mynett A, Novitch BG, Briscoe J (2007) Interpretation of the sonic hedgehog morphogen gradient 
by a temporal adaptation mechanism. Nature 450:717-720. CrossRef Medline

Dräger UC (1985) Birth dates of retinal ganglion cells giving rise to the crossed and uncrossed optic projections in the mouse. Proc R Soc Lond 224:57-77. CrossRef Medline

Dräger UC, Olsen JF (1980) Origins of crossed and uncrossed retinal projections in pigmented and albino mice. J Comp Neurol 191:383-412. CrossRef Medline

Erkman L, Yates PA, McLaughlin T, McEvilly RJ, Whisenhunt T, O'Connell SM, Krones AI, Kirby MA, Rapaport DH, Bermingham JR, O'Leary DD, Rosenfeld MG (2000) A POU domain transcription factor-dependent program regulates axon pathfinding in the vertebrate visual system. Neuron 28:779-792. CrossRef Medline

Erskine L, Herrera E (2007) The retinal ganglion cell axon's journey: insights into molecular mechanisms of axon guidance. Dev Biol 308: 1-14. CrossRef Medline

Erskine L, Reijntjes S, Pratt T, Denti L, Schwarz Q, Vieira JM, Alakakone B, Shewan D, Ruhrberg C (2011) VEGF signaling through neuropilin 1 guides commissural axon crossing at the optic chiasm. Neuron 70:951-965. CrossRef Medline

Esteve P, Bovolenta P (2006) Secreted inducers in vertebrate eye development: more functions for old morphogens. Curr Opin Neurobiol 16:1319. CrossRef Medline

Esteve P, Trousse F, Rodríguez J, Bovolenta P (2003) SFRP1 modulates retina cell differentiation through a $\beta$-catenin-independent mechanism. J Cell Sci 116:2471-2481. CrossRef Medline

Fabre PJ, Shimogori T, Charron F (2010) Segregation of ipsilateral retinal ganglion cell axons at the optic chiasm requires the Shh receptor Boc. J Neurosci 30:266-275. CrossRef Medline

García-Frigola C, Herrera E (2010) Zic2 regulates the expression of Sert to modulate eye-specific refinement at the visual targets. EMBO J 29:31703183. CrossRef Medline

Garcia-Frigola C, Carreres MI, Vegar C, Herrera E (2007) Gene delivery into mouse retinal ganglion cells by in utero electroporation. BMC Dev Biol 7:103. CrossRef Medline

García-Frigola C, Carreres MI, Vegar C, Mason C, Herrera E (2008) Zic2 promotes axonal divergence at the optic chiasm midline by EphB1-dependent and -independent mechanisms. Development 135:1833-1841. CrossRef Medline

Godement P, Vanselow J, Thanos S, Bonhoeffer F (1987) A study in developing visual systems with a new method of staining neurones and their processes in fixed tissue. Development 101:697-713. Medline

Hartman TR, Zinshteyn D, Schofield HK, Nicolas E, Okada A, O'Reilly AM (2010) Drosophila Boi limits Hedgehog levels to suppress follicle stem cell proliferation. J Cell Biol 191:943-952. CrossRef Medline

Hatini V, Huh SO, Herzlinger D, Soares VC, Lai E (1996) Essential role of stromal mesenchyme in kidney morphogenesis revealed by targeted disruption of Winged Helix transcription factor BF-2. Genes Dev 10:1467-1478. CrossRef Medline

Hayhurst M, Gore BB, Tessier-Lavigne M, McConnell SK (2008) Ongoing sonic hedgehog signaling is required for dorsal midline formation in the developing forebrain. Dev Neurobiol 68:83-100. CrossRef Medline

Herrera E, Brown L, Aruga J, Rachel RA, Dolen G, Mikoshiba K, Brown S, Mason CA (2003) Zic2 patterns binocular vision by specifying the uncrossed retinal projection. Cell 114:545-557. CrossRef Medline

Herrera E, Marcus R, Li S, Williams SE, Erskine L, Lai E, Mason C (2004) Foxd 1 is required for proper formation of the optic chiasm. Development 131:5727-5739. CrossRef Medline

Jaubert-Miazza L, Green E, Lo FS, Bui K, Mills J, Guido W (2005) Structural and functional composition of the developing retinogeniculate pathway in the mouse. Vis Neurosci 22:661-676. CrossRef Medline

Lee CS, May NR, Fan CM (2001) Transdifferentiation of the ventral retinal pigmented epithelium to neural retina in the growth arrest specific gene 1 mutant. Dev Biol 236:17-29. CrossRef Medline

Lee R, Petros TJ, Mason CA (2008) Zic2 regulates retinal ganglion cell axon avoidance of ephrinB2 through inducing expression of the guidance receptor EphB1. J Neurosci 28:5910-5919. CrossRef Medline

Lek M, Dias JM, Marklund U, Uhde CW, Kurdija S, Lei Q, Sussel L, Rubenstein JL, Matise MP, Arnold HH, Jessell TM, Ericson J (2010) A homeodomain feedback circuit underlies step-function interpretation of a Shh morphogen gradient during ventral neural patterning. Development 137: 4051-4060. CrossRef Medline
McCarthy RA, Barth JL, Chintalapudi MR, Knaak C, Argraves WS (2002) Megalin functions as an endocytic sonic hedgehog receptor. J Biol Chem 277:25660-25667. CrossRef Medline

MuX, Klein WH (2004) A gene regulatory hierarchy for retinal ganglion cell specification and differentiation. Semin Cell Dev Biol 15:115-123. CrossRef Medline

Mu X, Beremand PD, Zhao S, Pershad R, Sun H, Scarpa A, Liang S, Thomas TL, Klein WH (2004) Discrete gene sets depend on POU domain transcription factor Brn3b/Brn-3.2/POU4f2 for their expression in the mouse embryonic retina. Development 131:1197-1210. CrossRef Medline

Nagai T, Aruga J, Minowa O, Sugimoto T, Ohno Y, Noda T, Mikoshiba K (2000) Zic2 regulates the kinetics of neurulation. Proc Natl Acad Sci U S A 97:1618-1623. CrossRef Medline

Okada A, Charron F, Morin S, Shin DS, Wong K, Fabre PJ, Tessier-Lavigne M, McConnell SK (2006) Boc is a receptor for sonic hedgehog in the guidance of commissural axons. Nature 444:369-373. CrossRef Medline

Pak W, Hindges R, Lim YS, Pfaff SL, O’Leary DD (2004) Magnitude of binocular vision controlled by islet- 2 repression of a genetic program that specifies laterality of retinal axon pathfinding. Cell 119:567-578. CrossRef Medline

Petros TJ, Rebsam A, Mason CA (2008) Retinal axon growth at the optic chiasm: to cross or not to cross. Annu Rev Neurosci 31:295-315. CrossRef Medline

Petros TJ, Shrestha BR, Mason C (2009) Specificity and sufficiency of EphB1 in driving the ipsilateral retinal projection. J Neurosci 29:3463-3474. CrossRef Medline

Quina LA, Pak W, Lanier J, Banwait P, Gratwick K, Liu Y, Velasquez T, O'Leary DD, Goulding M, Turner EE (2005) Brn3a-expressing retinal ganglion cells project specifically to thalamocortical and collicular visual pathways. J Neurosci 25:11595-11604. CrossRef Medline

Rebsam A, Petros TJ, Mason CA (2009) Switching retinogeniculate axon laterality leads to normal targeting but abnormal eye-specific segregation that is activity dependent. J Neurosci 29:14855-14863. CrossRef Medline

Rebsam A, Bhansali P, Mason CA (2012) Eye-specific projections of retinogeniculate axons are altered in albino mice. J Neurosci 32:4821-4826. CrossRef Medline

Ribes V, Balaskas N, Sasai N, Cruz C, Dessaud E, Cayuso J, Tozer S, Yang LL, Novitch B, Marti E, Briscoe J (2010) Distinct Sonic Hedgehog signaling dynamics specify floor plate and ventral neuronal progenitors in the vertebrate neural tube. Genes Dev 24:1186-1200. CrossRef Medline

Rohr KB, Schulte-Merker S, Tautz D (1999) Zebrafish zicl expression in brain and somites is affected by BMP and hedgehog signalling. Mech Dev 85:147-159. CrossRef Medline

Sakagami K, Gan L, Yang XJ (2009) Distinct effects of Hedgehog signaling on neuronal fate specification and cell cycle progression in the embryonic mouse retina. J Neurosci 29:6932-6944. CrossRef Medline

Sánchez-Arrones L, Cardozo M, Nieto-Lopez F, Bovolenta P (2012) Cdon and Boc: two transmembrane proteins implicated in cell-cell communication. Int J Biochem Cell Biol 44:698-702. CrossRef Medline

Sánchez-Camacho C, Bovolenta P (2008) Autonomous and nonautonomous Shh signalling mediate the in vivo growth and guidance of mouse retinal ganglion cell axons. Development 135:3531-3541. CrossRef Medline

Sánchez-Camacho C, Bovolenta P (2009) Emerging mechanisms in morphogen-mediated axon guidance. BioEssays 31:1013-1025. CrossRef Medline

Sanek NA, Taylor AA, Nyholm MK, Grinblat Y (2009) Zebrafish zic2a patterns the forebrain through modulation of Hedgehog-activated gene expression. Development 136:3791-3800. CrossRef Medline

Stecca B, Ruiz i Altaba A (2010) Context-dependent regulation of the GLI code in cancer by hedgehog and non-hedegehog signals. J Mol Cell Biol 2:84-95. CrossRef Medline

Tenzen T, Allen BL, Cole F, Kang JS, Krauss RS, McMahon AP (2006) The cell surface membrane proteins Cdo and Boc are components and targets of the Hedgehog signaling pathway and feedback network in mice. Dev Cell 10:647-656. CrossRef Medline

Tian NM, Pratt T, Price DJ (2008) Foxg1 regulates retinal axon pathfinding by repressing an ipsilateral program in nasal retina and by causing optic chiasm cells to exert a net axonal growth-promoting activity. Development 135:4081-4089. CrossRef Medline

Traiffort E, Moya KL, Faure H, Hässig R, Ruat M (2001) High expression 
and anterograde axonal transport of aminoterminal sonic hedgehog in the adult hamster brain. Eur J Neurosci 14:839-850. CrossRef Medline

Trousse F, Martí E, Gruss P, Torres M, Bovolenta P (2001) Control of retinal ganglion cell axon growth: a new role for Sonic hedgehog. Development 128:3927-3936. Medline

Wang SW, Mu X, Bowers WJ, Kim DS, Plas DJ, Crair MC, Federoff HJ, Gan L, Klein WH (2002) Brn3b/Brn3c double knockout mice reveal an unsuspected role for Brn3c in retinal ganglion cell axon outgrowth. Development 129:467-477. Medline
Wang Y, Dakubo GD, Thurig S, Mazerolle CJ, Wallace VA (2005) Retinal ganglion cell-derived sonic hedgehog locally controls proliferation and the timing of RGC development in the embryonic mouse retina. Development 132:5103-5113. CrossRef Medline

Williams SE, Mann F, Erskine L, Sakurai T, Wei S, Rossi DJ, Gale NW, Holt CE, Mason CA, Henkemeyer M (2003) Ephrin-B2 and EphB1 mediate retinal axon divergence at the optic chiasm. Neuron 39: 919-935. CrossRef Medline 